\title{
CURQVignettes
}

\section{Redesign of a Research Methods Course in Psychology: A Model for Teaching and Integrating Undergraduate Research}

Nicole J. Bies-Hernandez, Nora D. Dunbar, Gregory L. Busath, Matthew D. Anderson, John J. Houser,

Northern Arizona University, nicole.bies-hernandez@nau.edu

Courses in statistics and research methods serve as foundations for more advanced courses for undergraduate psychology majors. For the past three years, we have engaged in a collaborative redesign of our Research Methods in Psychology course to provide a standardized approach to course delivery that incorporates innovative practices for teaching undergraduate research. We were fortunate that the need for the redesign of this course occurred in conjunction with our department's adoption of learning goals that aligned with those presented in the APA Guidelines for the Undergraduate Psychology Major (American Psychological Association, 2013). The redesign of this course has allowed us to better incorporate learning goals related to scientific inquiry and critical thinking, ethical responsibility, communication, and professional development. It also has helped us promote the importance of the skills developed in this course as necessary for students to become effective consumers of research.

We have put effort into establishing and communicating expectations to students by creating and refining, as a group, the learning outcomes for this course and a set of standardized rubrics for all major course requirements (e.g., drafts for all sections of the final paper, poster, and presentation). The restructuring has allowed us to continue our focus on providing students with continual feedback and support from faculty, teaching assistants, and classmates throughout all aspects of the research process, including creating, conducting, writing about, and presenting the project.

The steering committee for the redesign met before the start of each semester and then weekly throughout the semester. Arriving at consensus regarding learning outcomes, assignments, and rubrics required diplomacy and compromise by everyone, but the collaborative process resulted in course materials that were well understood, had strong support, and could be implemented with fidelity. The consensus-building process illuminated the strengths of individual faculty, enhanced respect and rapport among faculty, and continues to provide a strong foundation as the course materials evolve. The consistency of assignments and their implementation helped strengthen the links between the Research Methods in Psychology course and both prerequisite courses (e.g.,
Introduction to Statistics in Psychology) and subsequent upper-level courses (e.g., Senior Capstone in Psychology).

One of the strongest aspects of this redesign is that it gives students an authentic research experience by requiring student groups, under the supervision of course faculty, to obtain approval for their proposed research before they can conduct their class project, and by requiring them to construct and present a research poster at a campus symposium. Students complete the modules in the Social and Behavioral Research Basic Course using the Collaborative Institutional Training Initiative in order to review ethical principles, including those presented in the Belmont report (National Commission for the Protection of Human Subjects of Biomedical and Behavioral Research, 1979). They also receive a briefing on the history and role of the institutional review board from a representative of our IRB.

Additionally, in their research groups, students complete an IRB application (including a consent form and debriefing document) that mimics the application form used by researchers at the university. Their application is then reviewed by the faculty who teach the course to ensure that the proposed research meets the criteria of being a "class project" (i.e., minimal risk with non-identifiable data and no contribution to generalizable knowledge). Although all research in this research-methods course is designed to be a "class project," students do have limited within-institution dissemination outlets (i.e., an internal symposium and Northern Arizona University's peer-reviewed, online undergraduate journal).

Every semester, all of the undergraduates in this class (usually between 120 and 150 students) present a professional-quality poster (in small research groups of three to five students) at the College of Social and Behavioral Sciences fall symposium or at the university's undergraduate symposium in the spring. Both of these symposia allow students to present their research through a conference-style poster presentation to their peers, professors, and the university and city communities. These "stand-and-deliver" experiences provide students with a broad audience beyond the usual presentation of their research in class or at a departmental event-opportunities that most students would not have experienced without this course.

Most recently, the number of presentations from this class accounted for approximately 30 percent of the presentations made by undergraduates in our department at the university-wide symposium and 10 percent of the undergraduate presentations made at this event by students in our college. Together, these components of the course provide students 
with a more genuine research experience, one that is consistent with the experience of an academic presenter at a professional conference.

This redesigned model has also helped to create a culture in which research is valued and psychology is viewed as a science. We now have a directive to increase opportunities for research that will be infused into upper-level courses in the major. Last semester, 88.89 percent of instructors of upperlevel courses incorporated skills and knowledge related to research methods into their courses (e.g., having students use library resources to conduct an effective literature search or synthesizing findings across multiple research articles). Instructors have also designed assignments that required students to collect and analyze data on a small scale, and then assess the validity and reliability of established measures and, ultimately, create and present an evidence-based poster or paper.

Data from our annual senior exit survey $(n=190)$ suggest the majority of our students continue to have meaningful research experiences after completing our redesigned research-methods course, with 95 percent reviewing primary scientific literature, 75 percent contributing to a poster or paper presented at a conference, and 64 percent attending a conference where their research was presented. These are remarkably high percentages, given that only 26.15 percent of students surveyed reported participating in our undergraduate research experience course, in which students work on original research with faculty. Thus, the practices incorporated into this redesign of the undergraduate research methods in psychology course provide a strong model for both teaching research methods and incorporating meaningful undergraduate research experiences into the major.

\section{References \\ American Psychological Association. 2013. APA Guidelines for the Undergraduate Psychology Major: Version 2.0. Accessed February 1, 2016. http://www.apa.org/ed/precollege/undergrad/index.aspx doi: 10.1037/ e504792014-001.}

National Commission for the Protection of Human Subjects of Biomedical and Behavioral Research. 1979. The Belmont Report: Ethical Principles and Guidelines for the Protection of Human Subjects of Research. Washington, DC: U.S. Department of Health, Education, and Welfare. Accessed February 1, 2016. http://www.hhs.gov/ohrp/regulations-and-policy/belmont-report/

doi:10.18833/curq/37/2/9

\section{A Community Model for Course-based Student Research That Advances Faculty Scholarship}

\author{
Emily Wiley, Douglas L. Chalker
}

Claremont McKenna, Pitzer, and Scripps Colleges, ewiley@ kecksci.claremont.edu, Washington University in St. Lovis, dchalker@wustl.edu

Educator-scientists are well aware of the many pedagogical benefits of engaging undergraduates in original scientific inquiry. However, doing so in a classroom setting to reach more students is challenging, time-intensive, hard to sustain, and intellectually draining for busy faculty members who struggle to balance the demands of teaching and research. Despite their best intentions, many faculty members who teach laboratory courses resort to straightforward "cookbook" lab exercises that require little to no problem solving and have ready-to-go teaching materials but do not provide students with experience in original inquiry.

To address these challenges, we formed a vibrant learning community of faculty members at multiple institutions. In our group, the Ciliate Genomics Consortium (CGC), all faculty members use a common model organism-Tetrahymena thermophila, a common single-celled inhabitant of pond water-in their research. Over the past 11 years, the CGC has developed a modular curriculum that exposes undergraduates to original research, contributes to scientific knowledge, and advances the varied research interests of participating faculty members.

The CGC curriculum includes five core modules using Tetrahymena: testing in silico gene models by reverse transcriptase polymerase chain reaction, determining gene expression profiles, assessing effects of gene knockouts, determining protein localization, and identifying protein interaction partners. Each faculty member may apply any combination of modules (designed for standard three- or four-hour laboratory sessions) to study any set of genes relevant to his or her particular research interests. We designed the modules to be highly flexible so faculty members can use them to address a broad range of biological questions in cell biology, molecular biology, genetics, biochemistry, and introductory biology courses.

For example, one class might use the protein localization module to investigate where proteins of interest act in a cell by tagging them with a fluorescent protein and examining localization in live cells by fluorescence microscopy. Another class might use the gene expression module to monitor changes in expression of selected genes when cells are exposed to environmental stressors or when growing in competition with another species. The flexible and modular 